\title{
SEISMIC RESPONSE OF CABLE-STAYED BRIDGE TOWER WITH SEMI-RIGID BASE CONNECTION MODELLING
}

\author{
Shehata E. ABDEL RAHEEM \\ Civil Engineering Dept., Faculty of Engineering, Assiut University, Assiut \\ 71516, Egypt, shehata_raheem@hotmail.com
}

(Received August 24, 2006 Accepted September 1, 2006)

The column base connections exhibit unpredictable semi-rigid behavior due to the fact that their basic components including base plate, anchor bolts and concrete foundation, are made from different material types and transmitting acting forces through unilateral multi-body contact. To address this need, this study seeks to develop a quite general base connection modelling capable of accurately representing material and geometrical nonlinear behavior of base connection, and its implementation in a time domain finite element seismic analysis through an incremental-iterative procedure is presented. A representative problem of cable-stayed bridges tower subjected to strong ground motion is analyzed. The maximum bearing stress on the concrete foundation as well as the tension force per anchor bolt that necessary to design the anchorage system is computed. The seismic responses of the tower structure with physical model of the base connection are compared to those of rigid base model. The semi-rigid connection model yields more economical solutions than rigid base model.

KEYWORDS: Seismic design; Semi-rigid base connection; Finite element model

\section{INTRODUCTION}

The base connection between columns and foundation is one of the most important elements in steel frame structures and has a great influence on the entire structural behavior as it is recognized from analytical studies [1 5] and experimental investigations $[6,7]$. The nonlinearities that arise due to the particular behavior of the connections components make the problem of the analysis of these structures very difficult [8, 9]. Many observers have reported damage at column bases during past earthquakes [10 13]. The Hyogoken Nanbu earthquake of January 1995 in Japan caused serious damage in a large number of steel structures. One of the reasons that have been registered is the failure of the column bases, resulting in such damage, which proved once again that special attention must be paid to the proper modelling and the right construction in such a way that failure should be avoided in these connections. 
The most common arrangement of the base connections is that a base plate welded at the bottom end of the column with anchor bolts embedded in the concrete, keeping the base-plate in contact with the foundation. Most of the modern codes [4, 14] give little information to the users about the real behavior of column bases, and practicing engineers usually treat this connection that represent the support conditions of the framed structures either as pinned or fixed, although it has been proved that these connections are semi-rigid and the real condition lies between these two extreme cases. The degree of semi-rigidity depends on the properties and the configuration of various elements that form the connection. Seismic design practice for this class of connections has not been well developed mainly because of the rather limited number of analytical and experimental studies. Most of the experimental studies have been performed on reduced scale specimens representing basic types of connections simulating a column welded to an exposed base plate, which in turn is connected to a concrete foundation through anchor bolts. The performance of the base connection depends on the cyclic performance of the anchors and the surrounding concrete foundation. Much research work is needed in order to better understand the seismic behavior and to formulate improved design procedures. The steel frames behavior could only be accomplished through nonlinear dynamic analyses of complete frame systems with actual support condition [15 17].

The behavior of steel framed structures depends on the performance of their connections. The design of base connections should capable of spreading the load so as to maintain the bearing pressures under the allowable values and connecting the base plate and column to the concrete foundation. But strong earthquake lateral forces can induce base overturning moments that exceed the available overturning resistance due to gravity loads causing base connection anchor bolts lift-off. The objective of this study is to develop an accurate and convenient model to predict the performance of cable-stayed bridge steel tower base connections under dynamic loadings, to address the problem of base plate lift-off and to formulate improved design procedures. A finite element methodology based on theoretical approach and computer simulations for nonlinear dynamic analysis problem including base connection modelling is presented. The base connection model takes into account: connection lift-off; the inelastic behavior of anchor bolts, material/geometrical nonlinear behavior of the base plate and nonlinear contact with concrete foundation through an incremental iterative procedure. The base connection is idealized by a spring system that considers connection various parameters of base plate, anchor bolts and material properties. A representative problem of cable-stayed bridge tower subjected to strong ground motion recoded at JR Takatori Station during Hyogoken Nanbu earthquake 1995 is analyzed. In addition, the maximum bearing stress on the concrete foundation as well as the seismic demand of the anchor bolt under strong earthquake that is the most important for design of the anchorage system is computed.

\section{FINITE ELEMENT MODEL}

\section{Tower Structure Modelling}

Based on detailed drawings of the bridge shown in Figure 1, a three-dimensional finite element model has been developed to represent the complex behavior of the bridge 
tower. The steel tower is taken out of the bridge and modeled as three-dimensional frame structure. A fiber flexural element is developed for characterization of the tower structure, in which the element incorporates both geometric and material nonlinearities. The stress-strain relationship of the beam element is modeled as bilinear type with kinematic strain hardening rule. The yield stress and the modulus of elasticity are equal to $355 \mathrm{MPa}$ (SM490Y) and 200GPa, respectively; the strain hardening in the plastic region is 0.01 .

This tower has nine cables in each side; the dead load of the stiffening girder is considered to be equivalent to the vertical component of the pretension force of the cables and acted vertically at the joint of cables. The inertia forces acting on the steel tower from the stiffening girders is neglected. For the numerical analysis, the geometry and the structural properties of the steel tower is shown in Figure 2. This tower has rectangular hollow steel section with internal stiffeners, which has different dimensions along tower height and its horizontal beam; the geometrical properties of the tower are summarized in Table 1. A spectral damping scheme of Rayleigh's damping is used to form damping matrix as a linear combination of mass and stiffness matrices, which effectively captures the tower structures damping and is also computationally efficient. The damping ratio corresponding to the frequencies of the fundamental in-plane and out-plane modes of tower free vibration is set to $2 \%$.

Inelasticity of the flexure element is accounted for by the division of the cross section into a number of fiber zones with uniaxial plasticity defining the normal stress-strain relationship for each zone, the element stress resultants are determined by integration of the fiber zone stresses over the cross section of the element. By tracking the center of the yield region, the evolution of the yield surface is monitored, and a stress update algorithm is implemented to allow accurate integration of the stress-strain constitutive law for strain increments, including full load reversals. To ensure path dependence of the solution, the implementation of the plasticity model for the implicit Newton Raphson equilibrium iterations employs a stress integration whereby the element stresses are updated from the last fully converged equilibrium state. The transformation between element local and global coordinates is accomplished through a vector translation of element forces and displacements based on the direction cosines of the current updated element coordinate system.

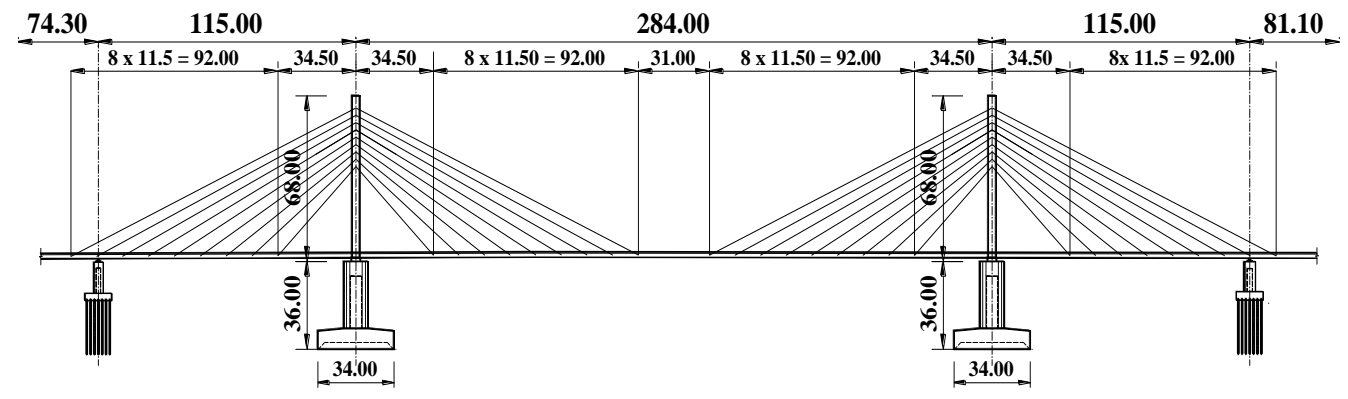

Figure 1: General view of the cable-stayed bridge $(\mathrm{m})$. 

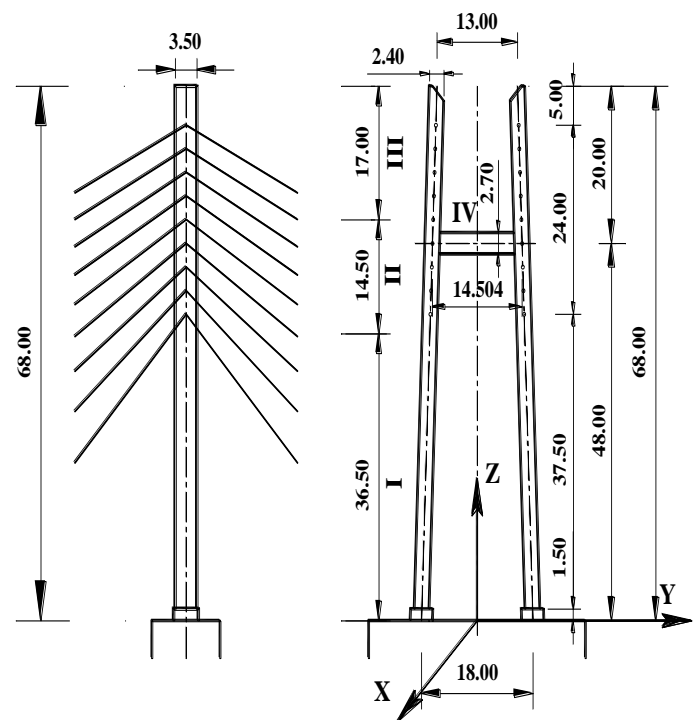

Figure 2: Steel tower Geometry of cable-stayed bridge (m).

Table 1: Cross sectional properties of tower.

\begin{tabular}{|c|c|c|c|c|}
\hline \multirow{2}{*}{$\begin{array}{l}\text { Cross sectional } \\
\text { properties }\end{array}$} & \multirow{2}{*}{ Area $\left(\mathrm{m}^{2}\right)$} & \multicolumn{2}{|c|}{ Moment of Inertia $\left(\mathrm{m}^{4}\right)$} & \multirow{2}{*}{$\begin{array}{l}\text { Torsion constant } \\
\left(\mathrm{m}^{4}\right)\end{array}$} \\
\hline & & $I_{y y}$ & $\boldsymbol{I}_{z z}$ & \\
\hline I & 0.4856 & 0.4842 & 0.7952 & 0.6391 \\
\hline II & 0.4560 & 0.4617 & 0.7567 & 0.6391 \\
\hline III & 0.4016 & 0.4050 & 0.6856 & 0.5976 \\
\hline IV & 0.4621 & 0.5680 & 0.7703 & 0.6903 \\
\hline
\end{tabular}

\section{Base Connection Components Modelling}

In recent decades, long span bridges such as cable-stayed bridges have gained much popularity. For these bridges, steel towers are preferred because of their efficient utilization of structural materials, improved speed of construction, earthquake resistance, and so on. Steel towers are usually fixed by multiple bolts to large anchor frame embedded in a concrete pier/footing, Figures $\mathbf{3}$ and $\mathbf{4}$ show sketch and details of tower base connection design drawings and the frame anchorage system, which provides a reliable and durable anchorage system.

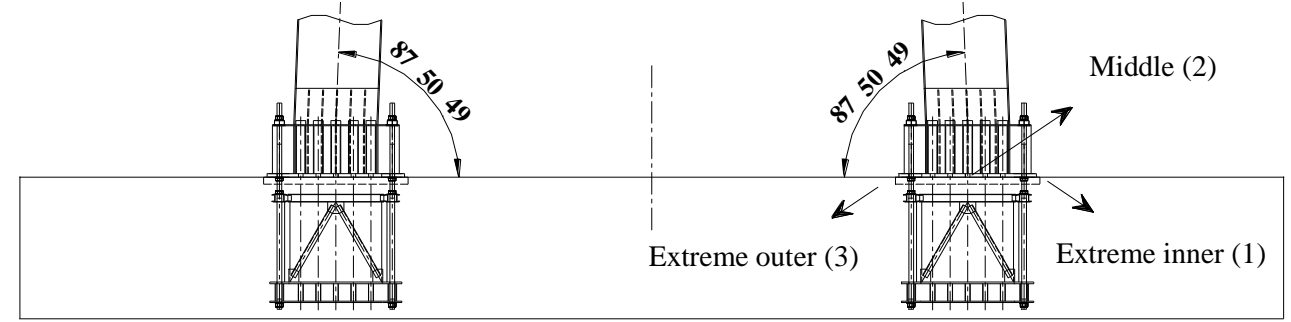

Figure 3: Sketch of the steel tower base connection. 


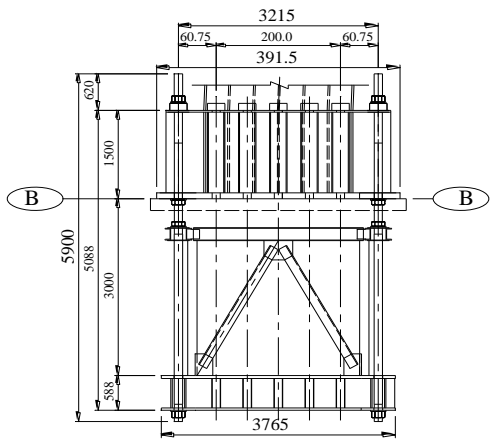

(a) Anchor frame

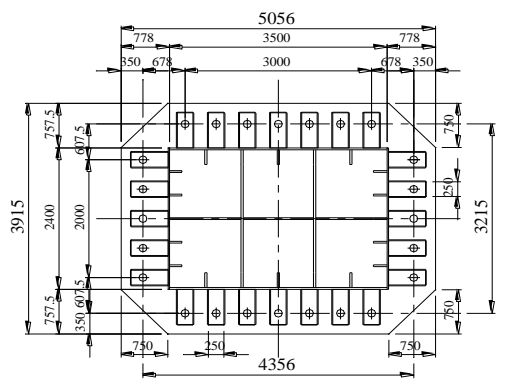

(b) Section B-B

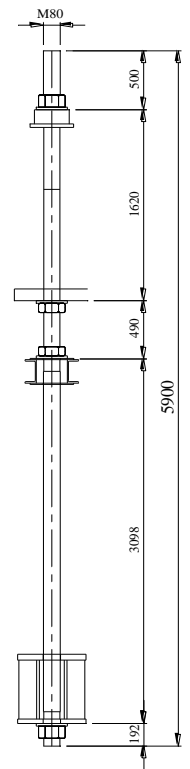

(c) Anchor bolt

Figure 4: Details of the steel tower base connection $(\mathrm{mm})$.

The column base connection consists of 24 anchor bolts arranged outside the tower leg flanges. To have sufficient weld to transmit the flange force into the base plate, additional weld is used through welding vertical plates to the flange and lengthening the anchor bolts. The complex nature of bolted base connections requires that advanced analysis techniques be used for seismic design. Finite element models of the connection components and their interaction have been developed. The sub-models enable a full nonlinear elasto-plastic analysis of the connection to be performed. A component spring model for base connections is proposed. This model incorporates deformations from tension bolt elongation, bending of base plate and concrete bearing underneath base plates. The individual components of the connection are model by a nonlinear spring. Then each of these springs is added to the system and its stiffness is assembled into the final overall stiffness of the connection. Figure $\mathbf{5}$ shows mechanical model of the base connection. In this model, the constitutive components of the base connection are represented by means of springs system that includes extensional springs to simulate the anchor bolts tension deformation, extensional springs to simulate the concrete in compression under the base plate. Each of these springs is characterized by its own deformability curve as an individual component, as shown in Figure 6 . The stiffness and resistance properties of the springs are calculated on the basis of the geometrical characteristics and the mechanical properties of the nonlinear constitutive material as given in Table 2. The stiffness of the concrete is determined by using an elastic half space. The anchor bolt pretension force and concrete compression pre-stress state as a result of self-equilibrium are considered. The nonlinear behavior of 
bolts is accounted for by an iterative numerical procedure. The steel bolt plays little or no part in the compressive behavior of concrete [18], thus the bolts in compression are replaced by concrete in the finite element analysis. The base plate is assumed rigid (EI $=\infty$ ) within tower leg dimensions, while the plate projections rigidity ( $E I)$ beyond the tower leg is computed. The anchor bolts are deigned to yield prior to anchorage rupture.

(a) Out-plane

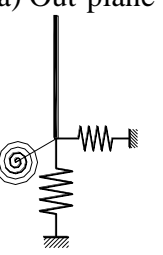

(b) In-plane

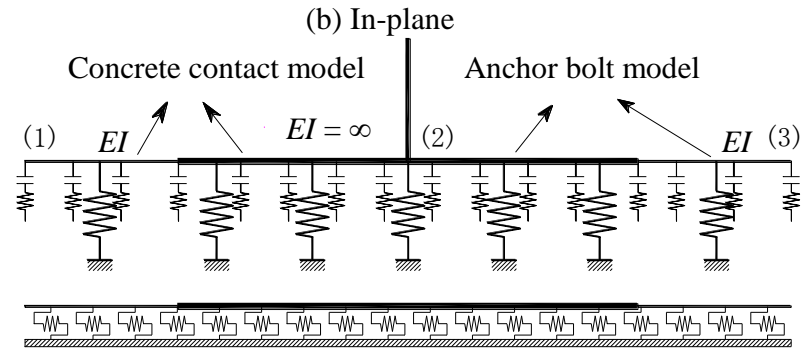

Figure 5: Tower base connection mechanical model.

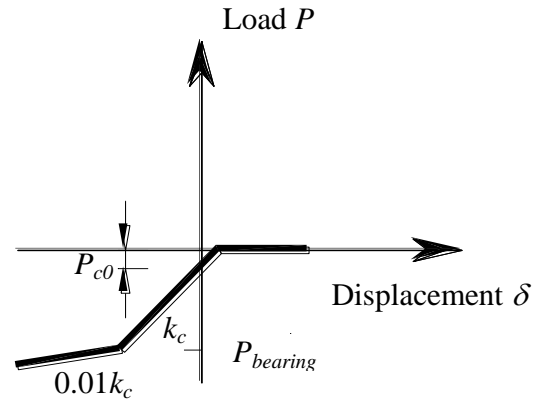

(a) Concrete contact model

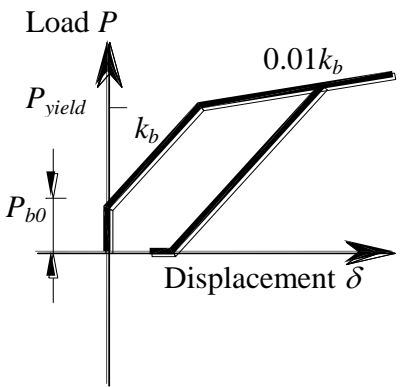

(b) Anchor bolt model

Figure 6: Base connection components constitutive models.

Table 2: base connection components properties.

\begin{tabular}{clc}
\hline Description & & Properties value \\
Anchor bolt & $E_{b}$ & $205.80 \mathrm{GPa}$ \\
& Stiffness $k_{b}$ & $201.2 \mathrm{MN} / \mathrm{m}$ \\
& Yield force / stress & $1.93 \mathrm{MN} / 440 \mathrm{MPa}$ \\
& Pre-tension force & $0.81 \mathrm{MN}$ \\
& Shear stress & $251.4 \mathrm{MPa}$ \\
& Steel / Diameter & $\mathrm{S} 45 \mathrm{C} / \mathrm{M} 80$ \\
Concrete foundation & $E_{c}$ & $24.50 \mathrm{GPa}$ \\
& Stiffness $k_{c}$ & $19.852 \mathrm{GPa} / \mathrm{m}$ \\
& Bearing stress & $20.58 \mathrm{MPa}$ \\
& Friction coefficient & 0.5 \\
Base plate & Steel & SM490Y \\
\hline
\end{tabular}




\section{NUMERICAL RESULTS AND DISCUSSION}

\section{Tower Global Response}

A finite element analysis of steel tower taking into account a more realistic model for the support conditions (Case II) including physical base connection stiffness is demonstrated and a comparison to simplified support condition modelling of fixed base (Case I) of fully rigid base connection assumption is presented. The resulting dynamic characteristics of the physical base model are significantly different from those of tower structure with a fixed base due to base connection components nonlinearity. The tower top acceleration and displacement responses are characterized by three intervals time history, along the first third, the studied cases have similar response with slight high acceleration spike and low displacement demand, along the second third, the tower seismic response is highly damped free vibration response with longer natural vibration, while the last third after 20 seconds has free vibration with slight low amplitude and residual plastic displacement drift decreases as illustrated in Figures 7 and 8. Also, at the early time of time history response before the formation of hysteretic damping through the inelastic deformation of base connection components, the displacement peak response significantly decreases due to connection flexibility compared to fully rigid of fixed base model, while the acceleration response slightly changes with overridden acceleration spike. Once the base connection components attain yielding, the hysteretic damping through connection components inelastic deformations growth start to affect the seismic response, which can be clarified from rapidly decaying after peak excursions of case II response compared to that of case I. The semi-rigidity of base connections influences the moments and forces distribution as well as drift of tower frame structure. Since the tower top displacement drift decrease $14 \%$ that of fixed base model, the tower shear and flexural demands slight decrease $3.7 \%$ and 7.6\%, respectively, as shown in Figures $\mathbf{9}$ and $\mathbf{1 0 .}$

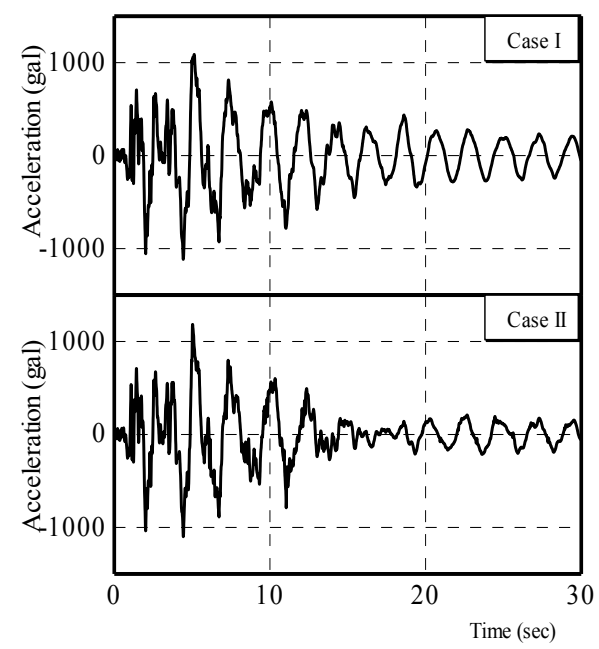

Figure 7: Tower top acceleration response

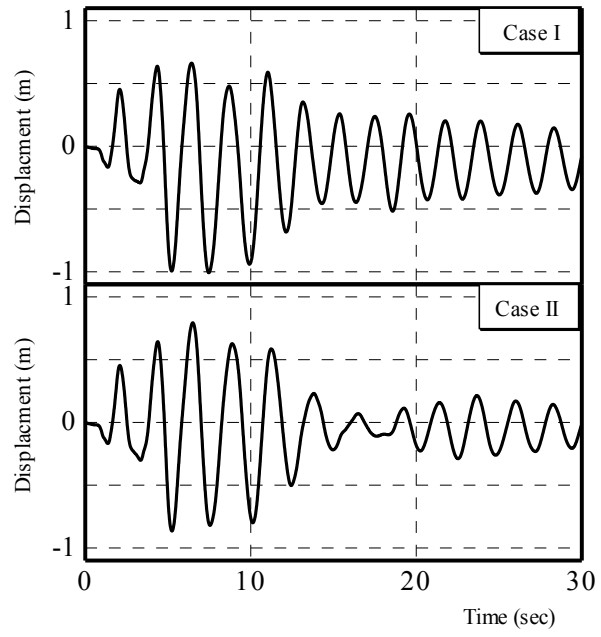

Figure 8: Tower top displacement response. 


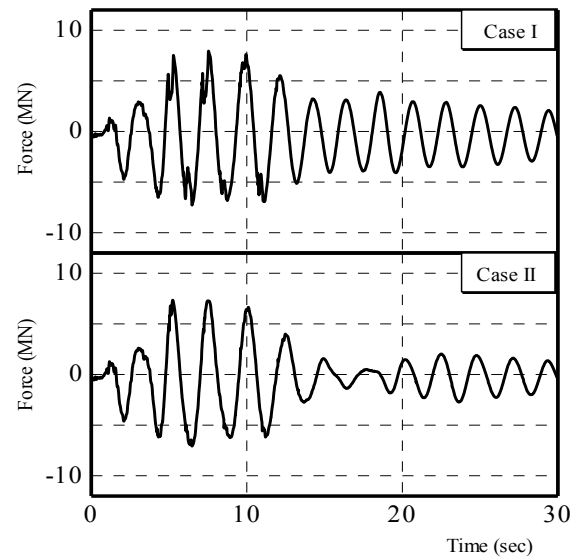

Figure 9: Tower base shear force time history.

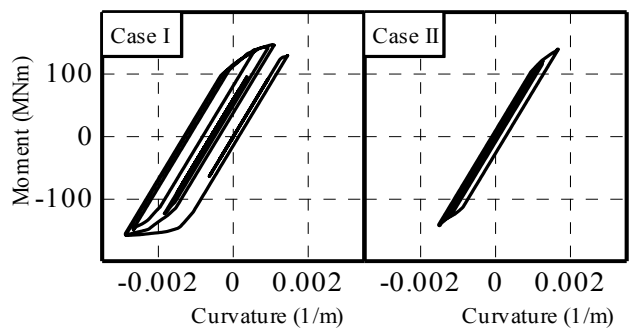

a) Tower base

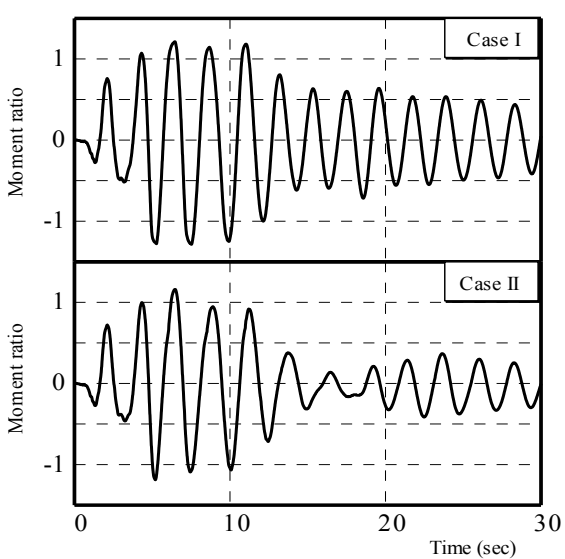

Figure 10: Tower base moment ratio time history.

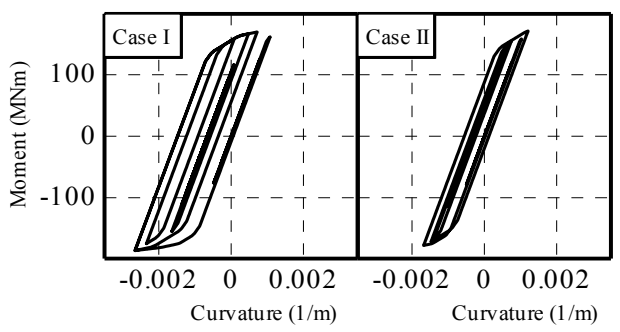

b) Horizontal beam end

Figure 11: Moment \& curvature relationship.

The moment time histories at tower base show the nature of the response to strong ground motion. The large pulse in the ground motion produces a two or three cycles of large force response, with the amplitude of moment or force decaying rapidly after the peak excursions. The shear force response of fixed base model is characterized by high response spike override the long period response pulse. It can be understood from the moment curvature relationship at tower base and horizontal beam end, Figure 11, that the fixed base model analysis displays a wide spread of inelastic deformation through tower elements and large ductility demands, which could lead to over conservative design. The base connections flexibility contribution to the curvature demand reduction could reach about $42 \%$

\section{Base Connection Behavior}

The base plate is tightened onto the concrete foundation by anchor bolts. Turning the nut on the threads will stretch the bolt to create a clamping force (preload or initial tension). The initial tension force will impart a compressive stress on the concrete foundation. At the initial state, the lower surface of the base plate is in contact with the concrete foundation. During seismic excitation, the base connection components begin to deform. As a result of the base plate deformation, some regions of the plate lift-off 
and lose contact with the foundation that cause nonlinear contact with concrete foundation and the load distribution change in the system. The elongated tensile anchor bolts deform greatly after their yield under tension force resulting in material and geometrical nonlinear behavior. The material nonlinearity is considered by the stress strain relationship of the fibers in a section. The geometric nonlinearity caused by the axial force is considered by the use of geometric stiffness matrix as well as the nonlinearity by the interaction between the axial force and the bending moment is considered.

The concrete foundation contact stress variation depends on base plate, concrete bearing and anchor bolts tensile stiffness. The base plate welded to the end of the column, the bolts and concrete foundation are deformable structural elements transmitting acting forces by the mutual and varying contact. The pre-stress due to connection self-equilibrium, dead weight and extreme contact stress distribution is presented in Figure 12.

It is obvious that the contact stress could exceed the concrete allowable bearing stress at extreme inner and outer of base connection base plate. The extreme stress distribution is significantly low where the base plate is assumed rigid within tower leg dimension, while the extreme stress has rapid and high rate growth through the plate projections beyond the tower leg where the base rigidity flexibility is considered. Since the yielding of the outer bolts may be allowed before crushing of the concrete occurs, the base lift-off is significantly large compared to concrete contact deformation as could clarified from the base plate lift-off and contact deformation in Figure 13. As the base plate begins to bend and to have rotation about an axis perpendicular to the plane of bending, the bolts on one side are in tension and some regions of plate lift-off and lose contact with the foundation while on the other side the base plate is in compression contact with concrete. The rocking vibration dominates the base plate deformation, the maximum lift-off occurs at extreme outer and reaches about $3.0 \mathrm{~cm}$, a corresponding maximum contact deformation at the extreme inner reaches $0.32 \mathrm{~cm}$.

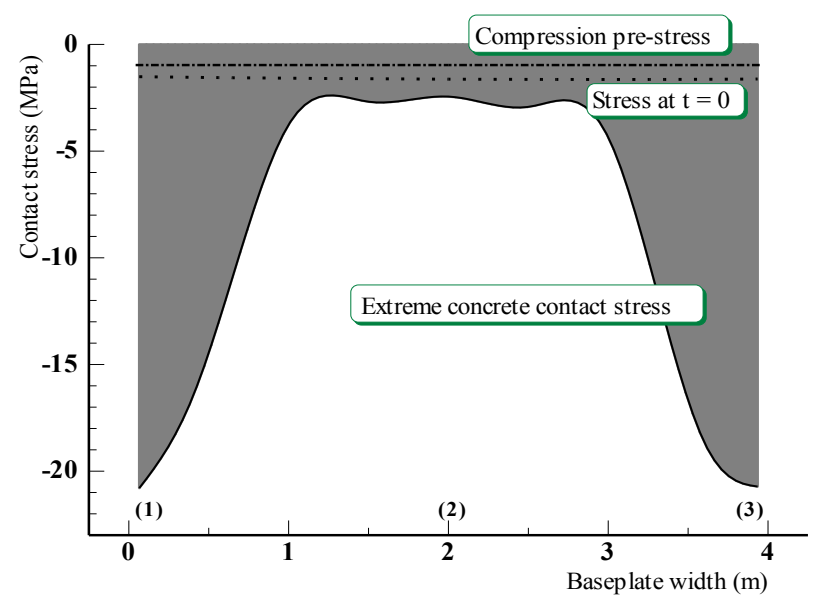

Figure 12: Extreme contact stress of concrete foundation . 


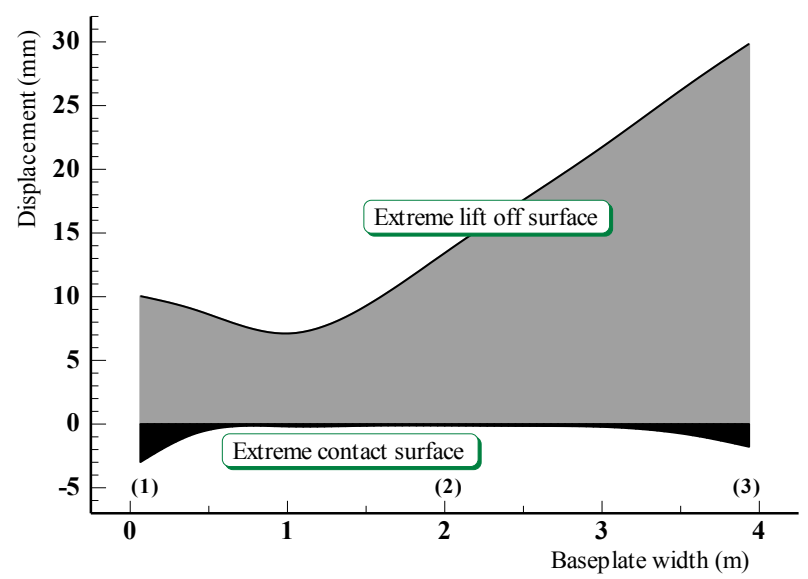

Figure 13: Extreme base plate lift-off and contact deformations.

Since the anchor bolt is bonded to the anchor frame embedded inside concrete foundation, it will provide rotational resistance at the base connection. Tensile force in the anchor bolt and bearing (compressive) force form a couple with very small lever arm. Thus, for a small load within the span a very large tensile force will develop in the anchor bolt. This force easily exceeds the yield force of the anchor bolts causing foundation concrete contact stress to exceed allowable bearing stress. The distribution of the tension loads among the anchor bolts depends on its location and base plate stiffness. The outer extreme anchor bolts experience large inelastic hysteretic deformation and large ductility demand required, while the inner anchor bolts endure smaller tension forces as a results smaller ductility and force demands.

The time history of anchor bolt tension force clarifies that the outer bolts experience tension yield four times, after the peaks excursion display long vibration highly damped response followed by free vibration; as shown in Figure 14. Once the anchor bolt tension force exceeds the yield force, the inelastic deformation growth could lead to energy dissipation through connection details. Also it can be seen how the applied external excitation is used to reflect the removal of bolt pre-tension force and quickly vanishes through the first few cycles within the first five seconds of the time history response. The dead weights have slight effects on bolt pre-tension force release.

The compatible deformation relationship between concrete and bolts could be obtained, as a result the anchor bolts experience severe tension yield at extreme outer, the foundation concrete experiences high contact compression stresses at extreme inner. The foundation concrete underneath the middle rigid base plate is characterizes by low contact stress within the allowable bearing stress. It is obvious that the bending of tower will cause most of the tensile bolts to elongate in such a way, the yield stress of bolts and bearing stress of concrete limits are broken. As a result of the nonlinear behavior of foundation concrete, the distribution of compressive contact stresses under the base plate violates the uniformly distributed approximation. The foundation concrete initial pre-stress as a self-equilibrium of base connection vanishes through the first cycle as shown in Figure 15. As the design tension yield force of anchor bolts 
system getting higher, the base plate and anchor bolts lift-off deformations decrease and the foundation contact stress and concrete deformations significantly getting higher, this could violate the concrete bearing stress.

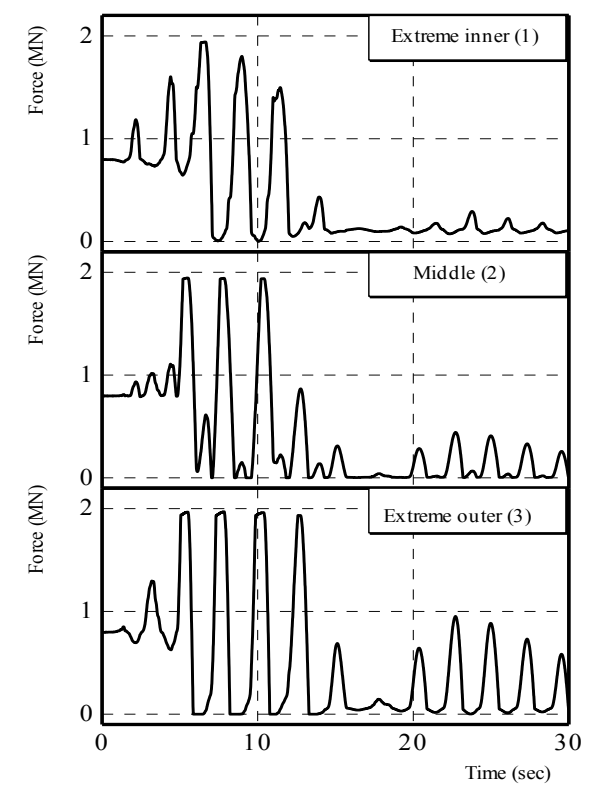

Figure 14: Anchor bolt load time history.

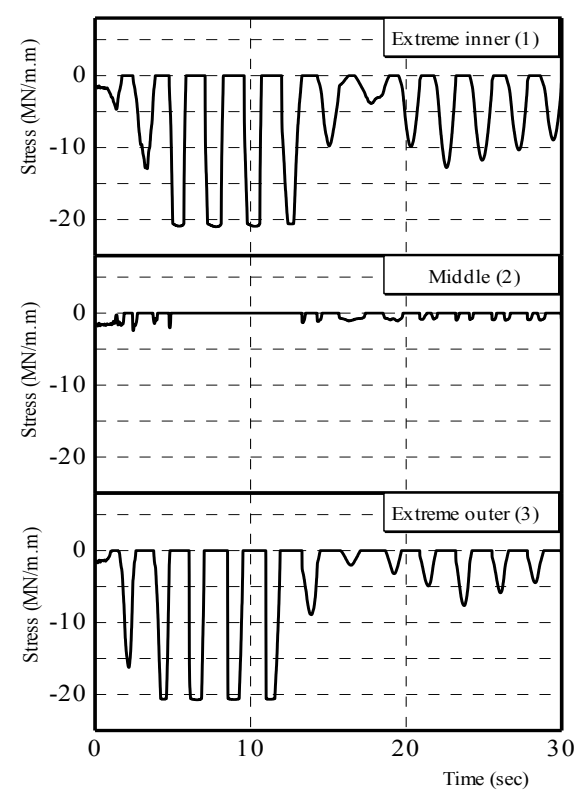

Figure 15: Foundation contact stress time history.

\section{CONCLUSIONS}

In this study, a mathematical modelling of tower base connection has been demonstrated and its implementation in a finite element nonlinear seismic analysis is presented. Numerical investigation, aiming at accurate description and evaluation of the base connection real behavior and its effects on the tower global response has been conducted. The model contains all the essential features including base plate elastoplastic behavior, concrete foundation contact and material nonlinearity and anchor bolt constitutive tension deformation without contribution in compression that characterize the base connection. The interface between the base plate and concrete foundation is modeled using contact elements. The bolts are represented with a group of elements reflecting the characteristics of real bolt behavior in an efficient manner.

The semi-rigidity of base connections influences the moments and forces distribution as well as drift of tower frame structure. The fixed base model analysis displays a wide spread of inelastic deformation through tower structural elements and large ductility demands, which could lead to over conservative design. The distribution of the tension loads among the anchor bolts depends on its location and base plate stiffness, the outer extreme anchor bolts experience large inelastic hysteretic deformations and large ductility demands. The bolt pre-tension force quickly vanishes through the first few cycles within the first five seconds of the time history response. The dead weights have slight effects on bolt pre-tension force release. The base lift-off is significantly large 
compared to concrete contact deformation; the distribution of compressive contact stresses under the base plate violates the uniformly distributed approximation. As the design tension yield force of anchor bolts system getting higher, the base plate and anchor bolts lift-off deformations decrease and the foundation contact stress and concrete deformations significantly getting higher, this could violate the concrete bearing stress.

\section{REFERENCES}

[1] Krishnamurthy, N. and Thambirathnam, D. (1990). "Finite element analysis of column base plates." Comput. Struct., 34, 215-223.

[2] Colson, A. (1991) "Theoretical modelling of semirigid connections behavior." J. Constr. Steel Research, 19, 213-224.

[3] Ermopoulos, J. and Stamatopoulos, G. (1996). "Mathematical modelling of column base plate connections." J. Constr. Steel Research, 36(2), 79-100.

[4] Ermopoulos, J. and Stamatopoulos, G. (1996). "Analytical modelling of column base plates under cyclic loading." J. Constr. Steel Research, 40(3), 225-238.

[5] Ermopoulos, J. and Michaltsos, G. (1998). "Analytical modelling of stress distribution under column base plates." J. Constr. Steel Research, 46(1-3), 46, paper No. 136.

[6] Targowski, R., Lamblin, D. and Guerlement, G. (1993). "Base plate column connection under bending: experimental and numerical study." J. Constr. Steel Research, 27, 37-54.

[7] Popov, E. P. and Takhirov, S. M. (2002). "Bolted large seismic steel-to-column connection part 1: experimental study." Eng. Struct., 24, 1523-1534.

[8] Rothert, H., Gebbeken, N. and Binder, B. (1992). "Non-linear three-dimensional finite element contact analysis of bolted connections in steel frames." Int. J. for Numer. Meth. in Eng., 34, 303-318.

[9] Piluso, V. and Faella, C. (2001). "Ultimate behavior of bolted T-stubs. I: Theoretical model." J. Struct. Eng., 127(6), 686-693.

[10] Astaneh-Asl, A., Bolt, B., McMullin, K., Donikian, R. R., Modjtahedi, D. and Cho, S. W. (1994). "Seismic Performance of Steel Bridges During the 1994 Northridge Earthquake, Report No. UCB/CEE-Steel-94/01." University of California, Berkeley.

[11] Nakashima, S., Kadoya, H. and Igarashi, S. (1995). "A report concerning damage to steel structures caused by the Hanshin Earthquake of January 17, 1995 in Japan - as to steel column bases and connections." Nordic Steel Construction Conference 1995, II, Sweden: Malmo, 835-842.

[12] Committee of Earthquake Engineering (1996). "The 1995 Hyogoken-Nanbu Earthquake, Investigation into Damage to Civil Engineering Structures.” Japan Society of Civil Engineers.

[13] Northridge Reconnaissance Team (1996). "Northridge Earthquake of January 17, 1994, Reconnaissance Report." EERI, Oakland, California, 25-47.

[14] Wald, F. (1993). "Column-base connections, a comprehensive state-of-the art review." Prague

[15] Jaspart, J. P. and Vadegans, D. (1998). "Application of component method to column bases.” J. Constr. Steel Research, 48, 89-106. 
[16] Nakashima, S. (1998). "Mechanical characteristics of exposed portions of anchor bolts in steel column bases under combined tension and shear." J. Constr. Steel Research, 46(1-3), 262-263, paper No. 277.

[17] Swanson, J. A. and Leon, R. T. (2001). "Stiffness modeling of bolted T-stub connection components." J. Struct. Eng., 27(5), 498-505.

[18] Yang, H. T. and Godfrey, D. A. (1969). "A non-linear analysis of the rotational stiffness of a nuclear steam generator foundation." Nuclear Eng. and Design, 10, 339-348.

\section{ردّ الفعل الزلزالي لبرج الجسر المشدود بكابلات مع نمذجة القاعدة بإتّصال نصف جاسيء}

تختص وصلات قاعدة البرج بسلوك نصف جاسيء لا يمكن التنبؤ به بسبب حقيقة أنّ وهيّ

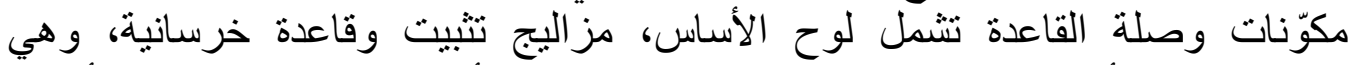

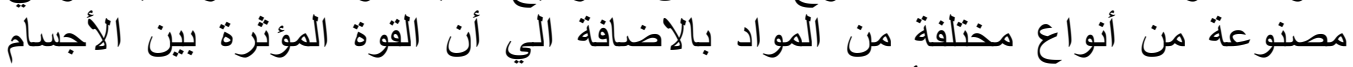

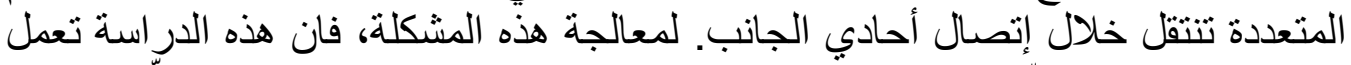

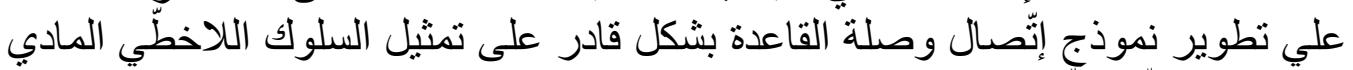

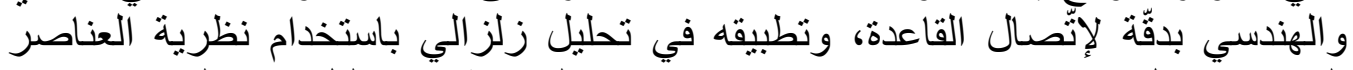

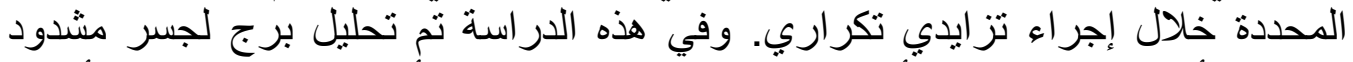

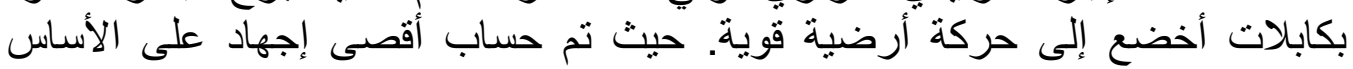

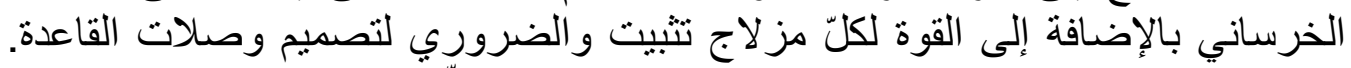

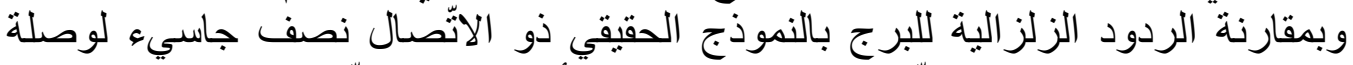

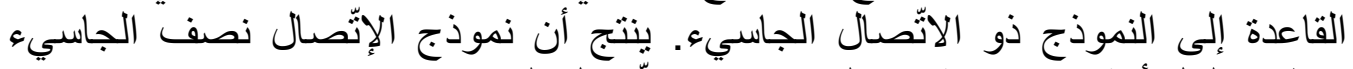

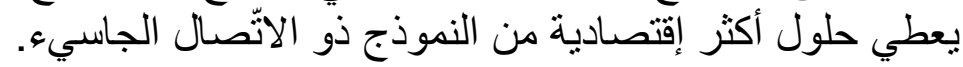

